\title{
The footprint of androgen sensitive serine protease (TMPRSS2) in gender mortality with COVID-19
}

\author{
Sepideh Zununi Vahed ${ }^{1}{ }^{\circledR}$, Shahram Ghiyasvand ${ }^{1}$, Ramin Tolouian $^{2}{ }^{\circledR}$, Hamid Noshad $^{1 \oplus}$, Audrey Tolouian $^{3}{ }^{\circledR}$, \\ Mohammadali Mohajel Shoja ${ }^{4}$, Mohammadreza Ardalan ${ }^{1 *} \mathbb{(}$ \\ ${ }^{1}$ Kidney Research Center, Tabriz University of Medical Sciences, Tabriz, Iran \\ ${ }^{2}$ Division of Nephrology, College of Medicine, University of Arizona, Tucson, AZ, USA \\ ${ }^{3}$ School of Nursing, The University of Texas at EI Paso, TX, USA \\ ${ }^{4}$ Department of Surgery, University of Illinois at Chicago-Metropolitan Group Hospitals (UIC-MGH), Chicago, Illinois, USA
}

\section{*Correspondence to \\ Prof. Mohammadreza Ardalan, Email: ardalan34@yahoo.com \\ Received 2 May 2020 \\ Accepted 13 May 2020 \\ Published online 19 May 2020 \\ Keywords: SARS-Cov-2, \\ TMPRSS2, nCov-19, \\ Androgen, Gender mortality, \\ COVID-19, Serine protease}

\section{Citation: Zununi} Vahed S, Ghiyasvand S, Tolouian R, Noshad H, Tolouian A, Mohajel Shoja M, Ardalan M. The footprint of androgen sensitive serine protease (TMPRSS2) in gender mortality with COVID-19. Immunopathol Persa. 2020;6(2):e27. DOI:10.34172/ ipp. 2020.27

\section{Abstract}

Male gender is an obvious risk factor for severe acute respiratory syndrome coronavirus 2 (SARS-CoV-2) infection and mortality rate is higher in men than women. Undoubtedly, gender-related behavioral factors, such as higher amounts of smoking, alcohol consumption, and biological differences in immune systems could make males more vulnerable. The role of androgen-responsive elements (AREs) of transmembrane serine proteases type II (TMPRSS2) gene as one of the major players of male dominancy in severe COVID-19 infection has been under appreciated and needs to be clarified.

\section{Introduction}

The clusters of severe acute respiratory syndrome coronavirus 2 (SARS-CoV-2) for the first time was reported in China in December 2019. The spread of the disease has created a huge global public health problem (1). The higher rate of mortality and severity of COVID-19 infection in the male compared to the female has been consistently shown in multiple countries $(2,3)$. The higher mortality rate in men might be explained by higher incidence of high-risk behaviors like alcohol consumption and smoking. The impact of pre-existing diseases such as diabetes, hypertension, cardiovascular disease, and chronic lung disease, and social differences are undeniable (4). It has been shown that male mice had a higher rate of susceptibility to SARS-CoV that was associated with a higher viral load in the accompaniment of extensive infiltration of neutrophils and macrophages into the lungs. Furthermore, administration of estrogen receptor antagonists proved a protective effect of estrogen receptor signaling in female mice. These observations may explain the differences in severity of disease based on gender in humans (5). It has been shown that in women, the higher serum IgG levels in the

\section{Key point}

The androgen-responsive elements (AREs) of TMPRSS2 gene might be an explanation for severity of COVID-19 infection and higher mortality in men.

early phase of SARS-CoV-2 infection have a significant positive impact in the outcome of COVID-19 infection (6). Sex hormones (androgens, progesterone, and estrogens) roles in the regulation of immune responses between the genders $(7,8)$. However, the exact underlying mechanism remains obscure and needs further investigation. In this paper, the role of androgen-responsive elements (AREs) of transmembrane serine proteases type II (TMPRSS2) gene as one of the major players of male dominancy in severe COVID-19 infection has been discussed.

\section{TMPRSS2 in physiology}

Membrane-bound serine proteases are a large family of enzymes with important physiologic roles in activation of extracellular molecule precursors. They have physiologic roles in food digestion, iron homeostasis, spermatogenesis, epithelial barrier integrity, and sex chromosome genes have significant

\footnotetext{
Copyright $\left({ }_{0} 2020\right.$ The Author(s); Published by Nickan Research Institute. This is an open-access article distributed under the terms of the Creative Commons Attribution License (http://creativecommons.org/licenses/by/4.0), which permits unrestricted use, distribution, and reproduction in any medium, provided the original work is properly cited.
} 
fluid balance and malignant growth. Viruses hijack the function of these enzymes to facilitate their own entry to the host cells (9-11). TMPRSS2 belongs to a membrane-anchored serine protease superfamily, but its physiological role is not fully understood. The secreted forms of TMPRSS2 have been found in human seminal prostasomes.

\section{TMPRSS2 and kidney sodium transport}

The epithelial sodium channel $(\mathrm{ENaC})$ is naturally expressed on the apical plasma membrane of different tissues such as colon, kidney, and lung. It is a rate-limiting channel for $\mathrm{Na}^{+}$absorption. In the airway system, secretion of the thin fluid film is mediated by the apical membrane chloride channels (CFTR) whilst its absorption requires ENaC activity $(12,13)$.

TMPRSS2 upregulates the $\mathrm{ENaC}$ activation in renal tubules and in theory, their inhibitors might be a novel therapeutic option for salt-sensitive hypertension $(10,14,15)$. TMPRSS2 as a protease break down the "inhibitory" lock between the $\alpha$ - and $\gamma$-subunits of the ENaC. Therefore, subsequent conformational changes increase $\mathrm{Na}^{+}$influx via the channel (14). Over the past two decades, it has been revealed that serine proteases have an important role in $\mathrm{ENaC}$ activation and sodium handling; and hypothetically inhibiting the TMPRSS2 might be an option for treatment of salt-sensitive hypertension, a condition in which $\mathrm{ENaC}$ are exceedingly activated (1416).

\section{TMPRSS2 and viral entry}

Several human respiratory viruses (e.g. influenza) use TMPRSS2 to enter the host cells. SARS-CoV, after attaching to ACE2 receptor, utilizes two cellular proteolytic systems to prime its S- protein and subsequent cell entry. Cathepsin $\mathrm{L}$, an endo/lysosomal host cell protease, facilitates the uptake of whole virion into the endosomes of the target cell. The second proteolysis system mediated through TMPRSS2 and facilitates the non-endosome entry of viral genome $(11,17)$.

\section{TMPRSS2 gene}

TMPRSS2 gene was identified in 1997 (18). The TMPRSS2 gene is around $44 \mathrm{~kb}$ in length, is located on human chromosome 21 (21q22.3) and consists of 14 exons. The full-length cDNA encodes a polypeptide with 492 amino acids. Human TMPRSS2 mRNA is expressed in different tissues, especially in epithelial cells of the lung, prostate, breast, bile duct, kidney, colon, pancreas, ovary, stomach, small intestine, and salivary gland. TMPRSS2 is synthesized in the form of inactive zymogens/pro-proteins and then is activated or auto activated by other proteases (19). One of the important characteristics of the TMPRSS2 gene is that several androgen receptor elements (AREs) are upstream of its transcription starting site. The exact mechanisms are not known, but two AREs at 13 and $60 \mathrm{~kb}$ upstream of the TMPRSS2 transcription start site have been described (20, 21). Androgen treatment increases TMPRSS2 zymogen activation in the cell culture and in a mouse xenograft model $(22,23)$. The human TMPRSS2 gene promoter has a 15-bp ARE at position -148 comparative to the putative transcription start site and, TMPRSS2 mRNA expression is consistently elevated in androgen-stimulated prostate cancer (LNCaP) cells $(23,24)$.

\section{TMPRSS2 and prostate cancer}

TMPRSS2 plays an important role in modulating the invasive behavior of prostate cancer (23). Fusion of androgen regulated TMPRSS2 promoter to the ERG oncogene leads to a high ERG expression that consequently intensifies the proliferative speed and invasiveness of prostate cancer. This fusion gene TMPRSS2/ERG (T/E) has been found in up to $60 \%$ of invasive prostate cancers and displays the importance of TMPRSS2 gene as an androgen responsive element that conducts the trigger to the fused oncogene (25).

\section{Conclusion and therapeutic remarks}

Male gender is an obvious risk factor for severe COVID-19 infection and male mortality is twice that of females. It seems that ARE in TMPRSS2 gene increases expression of TMPRSS2 in the lung's epithelial surface in males and makes them more susceptible to severe disease. It has been observed that wild type human coronavirus prefers non-endosomal, TMPRSS2-mediated entry rather than cathepsin L mediated-endosomal pathway (26). The inhibitors of TMPRSS2 appear to be a promising approach against SARS-CoV-2 viral infections. Camostat mesylate an FDA-approved medication inhibits the activity of TMPRSS2 enzyme but its entry into the lung is still debatable. Bromhexine hydrochloride, a mucolytic is another TMPRSS2 inhibitor that attenuates prostate cancer metastasis in mice models (27). Its entry into the lung tissue makes it a better potential inhibitor of TMPRSS2 in COVID-19-2 infection (Figure 1).

Authors' contribution

SZV, RT and MRA designed the study and prepared the first draft. MMSh, RT, AT and HN revised and edited the manuscript. All authors read and signed the final paper.

\section{Conflicts of interest}

The authors declared no competing interests.

\section{Ethical considerations}

Ethical issues including plagiarism, double publication, and redundancy have been completely observed by the authors.

Funding/Support

No financial support was provided. 


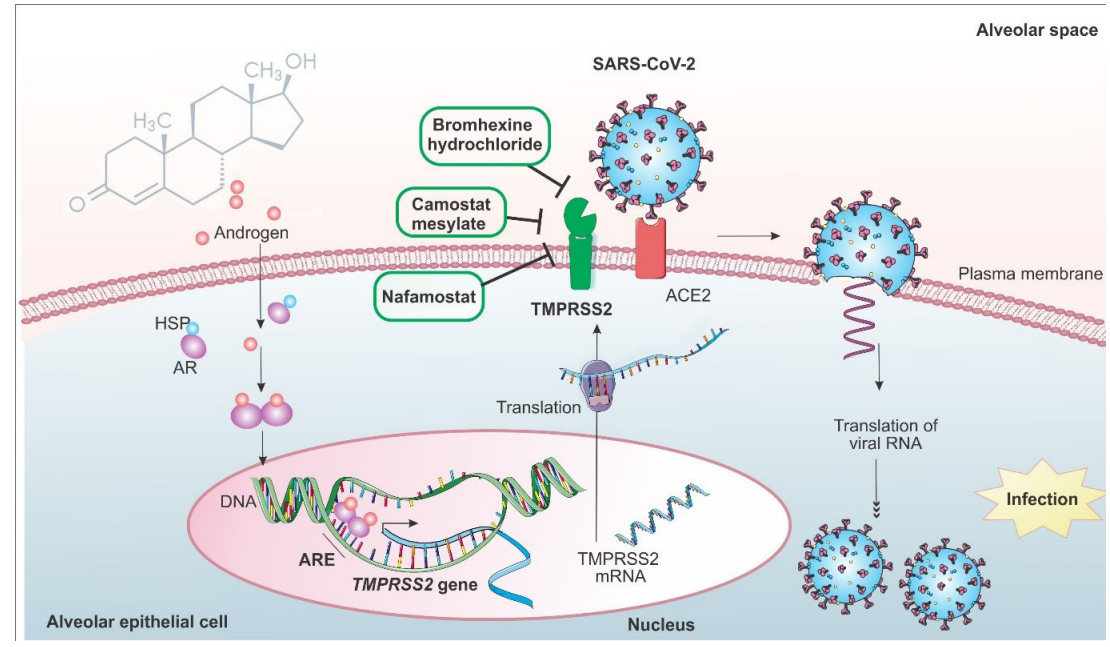

Figure 1. Androgen responsive elements (AREs) of TMPRSS2 gene. Androgen response elements (AREs) of TMPRSS2 gene is responsible for higher expression of TMPRSS2 enzyme on the epithelial cells membrane of respiratory system. It facilitates the non- endosome entry of SARSCov-2 into the lung tissue. Possible pharmacologic inhibitors of TMPRSS2 enzyme have been shown. AREs: Androgen responsive elements, AR: Androgen receptor, HSP: Heat shock protein.

\section{References}

1. Biswas A, Bhattacharjee U, Chakrabarti AK, Tewari DN, Banu H, Dutta S. Emergence of Novel Coronavirus and COVID-19: whether to stay or die out? Crit Rev Microbiol. 2020;46:182193. doi:10.1080/1040841x.2020.1739001.

2. Xie J, Tong Z, Guan X, Du B, Qiu H. Clinical characteristics of patients who died of coronavirus disease 2019 in China. JAMA. 2020;3:e205619. doi: 10.1001/jamanetworkopen.2020.5619

3. COVID-19 sex-disaggregated data tracker. Avaialble from: http://globalhealth5050.org/covid19/. Accessed May 13, 2020.

4. Sharma G, Volgman AS, Michos ED. Sex differences in mortality from COVID-19 pandemic: are men vulnerable and women protected? JACC Case Rep. 2020. doi:10.1016/j. jaccas.2020.04.027

5. Channappanavar R, Fett C, Mack M, Ten Eyck PP, Meyerholz DK, Perlman S. Sex-Based differences in susceptibility to severe acute respiratory syndrome coronavirus infection. J Immunol. 2017;198:4046-4053. doi: 10.4049/jimmunol.1601896

6. Zeng F, Dai C, Cai P, Wang J, Xu L, Li J, et al. A comparison study of SARS-CoV-2 IgG antibody between male and female COVID-19 patients: a possible reason underlying different outcome between sex. J Med Virol. 2020. doi: 10.1002/ jmv.25989

7. Klein SL, Flanagan KL. Sex differences in immune responses. Nat Rev Immunol. 2016;16:626-38. doi: 10.1038/nri.2016.90

8. Robinson DP, Huber SA, Moussawi M, Roberts B, Teuscher C, Watkins R, et al. Sex chromosome complement contributes to sex differences in coxsackievirus B3 but not influenza A virus pathogenesis. Biol Sex Differ. 2011;2:8. doi: 10.1186/20426410-2-8.

9. Hooper JD, Clements JA, Quigley JP, Antalis TM. Type II transmembrane serine proteases. Insights into an emerging class of cell surface proteolytic enzymes. J Biol Chem. 2001;276:857-60. doi: 10.1074/jbc.R000020200

10. Antalis TM, Buzza MS, Hodge KM, Hooper JD, Netzel-Arnett $\mathrm{S}$. The cutting edge: membrane-anchored serine protease activities in the pericellular microenvironment. Biochem J. 2010;428:325-46. doi: 10.1042/bj20100046

11. Limburg H, Harbig A, Bestle D, Stein DA, Moulton HM, Jaeger $\mathrm{J}$, et al. TMPRSS2 is the major activating protease of influenza A virus in primary human airway cells and influenza B virus in human type II pneumocytes. J Virol. 2019;93:e00649-19. doi:10.1128/jvi.00649-19

12. Galietta LJ. The TMEM1 6 protein family: a new class of chloride channels? Biophys J. 2009;97:3047-53. doi: 10.1016/j. bpj.2009.09.024.

13. Rossier BC, Stutts MJ. Activation of the epithelial sodium channel (ENaC) by serine proteases. Annu Rev Physiol. 2009;71:36179. doi: 10.1146/annurev.physiol.010908.163108.

14. Vuagniaux G, Vallet $V$, Jaeger NF, Hummler E, Rossier BC. Synergistic activation of $\mathrm{ENaC}$ by three membrane-bound channel-activating serine proteases (mCAP1, mCAP2, and mCAP3) and serum- and glucocorticoid-regulated kinase (Sgk1) in Xenopus Oocytes. J Gen Physiol. 2002;120:191-201. doi: 10.1085/jgp.20028598.

15. Kitamura K, Tomita K. Regulation of renal sodium handling through the interaction between serine proteases and serine protease inhibitors. Clin Exp Nephrol. 2010;14:405-10. doi: 10.1007/s10157-010-0299-7.

16. Antalis TM, Bugge TH, Wu Q. Membrane-anchored serine proteases in health and disease. Prog Mol Biol Transl Sci. 2011;99:1-50. doi: 10.1016/B978-0-12-385504-6.00001-4.

17. Hoffmann $M$, Kleine-Weber $H$, Schroeder $S$, Kruger $N$, Herrler T, Erichsen S, et al. SARS-CoV-2 cell entry depends on ACE2 and TMPRSS2 and is blocked by a clinically proven protease inhibitor. Cell. 2020;181:271-280. doi: 10.1016/j. cell.2020.02.052.

18. Paoloni-Giacobino A, Chen H, Peitsch MC, Rossier C, Antonarakis SE. Cloning of the TMPRSS2 gene, which encodes a novel serine protease with transmembrane, LDLRA, and SRCR domains and maps to 21q22.3. Genomics. 1997;44:30920. doi: 10.1006/geno.1997.4845.

19. Hoffmann M, Hofmann-Winkler H, Pöhlmann S, Priming Time: How Cellular Proteases Arm Coronavirus Spike Proteins, Activation of Viruses by Host Proteases. Activation of Viruses by Host Proteases. 2018:71-98. doi: 10.1007/978-3-31975474-1_4.

20. Wang Q, Li W, Liu XS, Carroll JS, Janne OA, Keeton EK, et al. A hierarchical network of transcription factors governs androgen receptor-dependent prostate cancer growth. Mol Cell. 2007;27(3):380-92. doi: 10.1016/j.molcel.2007.05.041.

21. Clinckemalie L, Spans L, Dubois V, Laurent M, Helsen C, 
Joniau S, et al. Androgen regulation of the TMPRSS2 gene and the effect of a SNP in an androgen response element. Mol Endocrinol. 2013;27:2028-40. doi: 10.1210/me.2013-1098.

22. Afar DE, Vivanco I, Hubert RS, Kuo J, Chen E, Saffran DC, et al. Catalytic cleavage of the androgen-regulated TMPRSS2 protease results in its secretion by prostate and prostate cancer epithelia. Cancer Res. 2001;61:1686-92.

23. Lin B, Ferguson C, White JT, Wang S, Vessella R, True LD, et al. Prostate-localized and androgen-regulated expression of the membrane-bound serine protease TMPRSS2. Cancer Res. 1999;59:4180-4.

24. Cai C, He HH, Chen S, Coleman I, Wang H, Fang Z, et al. Androgen receptor gene expression in prostate cancer is directly suppressed by the androgen receptor through recruitment of lysine-specific demethylase 1. Cancer Cell.
2011;20:457-71. doi: 10.1016/j.ccr.2011.09.001.

25. Clark J, Merson S, Jhavar S, Flohr P, Edwards S, Foster CS, et al. Diversity of TMPRSS2-ERG fusion transcripts in the human prostate. Oncogene. 2007;26(18):2667-73. doi: 10.1038/ sj.onc. 1210070

26. Shirato K, Kawase M, Matsuyama S. Wild-type human coronaviruses prefer cell-surface TMPRSS2 to endosomal cathepsins for cell entry. Virology. 2018;517:9-15. doi: 10.1016/j.virol.2017.11.012.

27. Lucas JM, Heinlein C, Kim T, Hernandez SA, Malik MS, True LD, et al. The androgen-regulated protease TMPRSS2 activates a proteolytic cascade involving components of the tumor microenvironment and promotes prostate cancer metastasis. Cancer Discov. 2014;4:1310-25. doi: 10.1158/2159-8290.Cd13-1010. 